\title{
Planned Contingent On Relationship
}

National Cancer Institute

\section{Source}

National Cancer Institute. Planned Contingent On Relationship. NCI Thesaurus. Code C93466.

A relationship between a planned activity and one of the following where all activities are intended to occur at some point in the course of a particular study: Another planned activity where the source activity does not occur unless the target activity has occurred; The defined outcome of another planned activity where the source activity does not occur unless the target activity outcome has occurred; A planned group of other criteria that may be composed of a mix of other activities, observation results and/or other groups. 